\title{
A Case-control Study to Investigate Variables associated with Incidents and Adverse Events in the Emergency Department
}

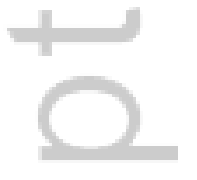 \\ Jamie Hendrie ${ }^{1}$, Michael Yeoh ${ }^{1}$, \\ Jo Richardson ${ }^{1}$, Andrew Blunt ${ }^{1}$, \\ Peter Davey ${ }^{2}$, \\ David Taylor ${ }^{3}$, \\ Antony Ugoni ${ }^{4}$ \\ ${ }^{1}$ Department of Emergency Medicine, Austin Health \\ ${ }^{2}$ Clinical Information Analysis and Reporting, Austin Health \\ ${ }^{3}$ Department of Medicine, University of Melbourne \\ ${ }^{4}$ Department of Physiotherapy, University of Melbourne
}

Correspondence: Dr J Hendrie, Emergency Department, Austin Health, Burgundy Rd, Heidelberg 3084, Victoria, Australia. Email: james.hendrie@austin.org.au Phone: 0394965000

J Hendrie MBBS, FACEM, MD, Senior Staff Specialist; M Yeoh MBBS, FACEM, Senior Staff Specialist, Director of Quality Assurance; J Richardson MBChB, FACEM, Staff Specialist, Deputy Director of Quality Assurance; A Blunt MBBS, FACEM, Staff Specialist; P Davey, Post Grad Dip Business Information Systems, Manager, Clinical Information Analysis and Reporting; D McD Taylor, MBBS, MD, MPH, DRCOG, FACEM, Professor; Antony Ugoni, MSc, Lecturer, Department of Physiotherapy

This is the author manuscript accepted for publication and has undergone full peer review but has not been through the copyediting, typesetting, pagination and proofreading process, which may lead to differences between this version and the Version of Record. Please cite this article as doi: $10.1111 / 1742-6723.12736$

This article is protected by copyright. All rights reserved. 


\section{Author's contribution to the paper:}

J Hendrie: designed the study, reviewed cases, collated the data, assisted with the subset analysis and wrote the paper.

M Yeoh: helped design the study, undertook the ethics submission, reviewed assigned cases to detect incidents and adverse events.

J Richardson: reviewed assigned cases to detect incidents and adverse events.

A Blunt: reviewed assigned cases to detect incidents and adverse events.

P Davey: interrogated the hospital computer system to provide demographic data on patients.

D McD Taylor: helped design the study, undertook the randomization process and allocation of cases, and performed the statistical analysis.

A Ugoni performed the multiple regression analysis.

Word Count of Main Text (excluding tables and boxes): 2490

The work was carried out at: Emergency Department, Austin Health, Burgundy Rd, Heidelberg 3084, Victoria, Australia.

MeSH Key Words:

Drug related side effects and adverse drug reactions

Errors, diagnostic

Errors, medical

Emergency Services, hospital

Human

This article is protected by copyright. All rights reserved. 


\section{INTRODUCTION}

The Emergency Department (ED) setting is a busy, stressful and challenging work environment. Patients often present with undifferentiated and complicated disease states that need to be managed expeditiously yet competently. Inherent among the responsibilities of ED staff is the accurate monitoring of incidents (Is, no harm sustained) and adverse events (AEs) (see Box 1). These can be used to inform procedural, investigational, education or staff changes in an attempt to minimize these events.

In a previous study of 3,222 ED patients, we reported a Total Event Rate (TER, combined I/AE rate) of $5.1 \% .{ }^{1,2}$ This comprised I and AE rates of $1.98 \%$ and $3.1 \%$, respectively. The most common events were drug reactions (1.35\%), which were usually associated with pre-ED management and were mostly not preventable. I/AEs arising within the ED were most commonly due to diagnostic error (1.2\%) and were largely preventable. $^{2,3}$ 
Wolff and Burke reviewed a sample of $2.7 \%$ of medical records to detect AEs in the ED. ${ }^{4}$ While many studies have simply documented I/AE rates, Wolff and Burke reported a reduction in $\mathrm{AE}$ rate following process changes in the ED. These changes reduced AEs from 3.26\% to $0.48 \%$ over 21 months.

Other studies have reported hospital-wide rates of AEs ranging from $3.7 \%$ for the Harvard Medical Practice Study (HMPS) to $16.6 \%$ by the Quality in Australian Health Care Study (QAHCS). ${ }^{5,6}$ The ED was the site of the AE in $2.9 \%$ and $1.5 \%$ in HMPS and QAHCS, respectively. ${ }^{6,7}$

Sprivulis et al. ${ }^{8}$ used linkage of ambulance, hospital and death registries to calculate citywide mortality rates of patients attending Perth EDs, innovating the term 'arrival density hazard' and the 'overcrowding hazard scale'. Their study demonstrated a linear relationship between the overcrowding hazard scale and 7-day mortality. Richardson and Guttmann also reported increased mortality and decline in other parameters with ED overcrowding and prolonged length of stay. ${ }^{9,10}$

Using pre-specified screening criteria, Klasco et $\mathrm{al}^{11}$ reported an overall incidence of error of $0.13 \%$ among all ED patients with an $\mathrm{AE}$ rate of 
$0.11 \%$. They acknowledge that the low rates reported were a function of their highly specific screening criteria.

The objective of this study was to describe and analyze I/AEs in the ED. We hypothesized that I/AE are associated with patient load and that diagnostic error would have high preventability and would be associated with events that occurred in ED.

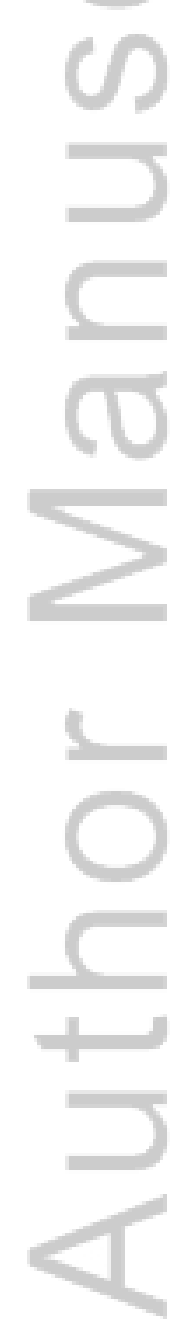

This article is protected by copyright. All rights reserved. 


\section{METHODS}

\section{Study design}

This was a case-control study of patients presenting to a tertiary level hospital ED between $1^{\text {st }}$ April 2012 and $31^{\text {st }}$ March 2013. The annual census for the period was 72,386 attendances. The study was approved by the hospital ethics committee.

At the beginning of every month, a random sample of $3 \%$ of all patients, who presented during the previous month, was selected using the random number function of the Excel spreadsheet. This was undertaken by one investigator (DT) who did not review the medical records and played no part in determining if I/AEs had occurred.

\section{Cases}

Four practicing emergency physicians reviewed an assigned proportion of patient medical records, making a judgment if I/AEs had occurred up until 30 days after presentation to the ED. Each patient's record was reviewed by a single consultant. Cases where a reviewer was in doubt were discussed by all investigators until a determination was made by consensus. 
The definitions of I/AEs we used were derived from QAHCS $^{6}$, but modified for the ED (Box 1 for these and other definitions). A 'prior event' is an I/AE that occurred prior to arriving in ED for the index presentation. The definition of diagnostic error was derived from Mosby's dictionary definition of 'diagnose', again modified to the ED setting. ${ }^{12}$

\section{Controls}

Unmatched controls were selected on a 2:1 basis. On the randomised patient list, controls were the two patients immediately below an identified case. If one of these two patients was themselves a case, the closest two patients on the list were selected as potential controls. If one potential control was subsequently found to have an I/AE, another control was sought. Given the randomization of the list, there was no time or other relationship between controls and cases.

\section{Study Data}

All patient data, including history, examination findings and diagnosis, was retrieved electronically. Times of arrival, seen by doctor, and departure to ward or home are routinely recorded. At the time of the study, MedTrak ${ }^{\circledR}$ was the ED operating system. Data was recorded on a 
hardcopy data collection instrument that was designed specifically for the study and was trialed and revised before use. It was similar to that used in similar studies. ${ }^{1,2}$ Data on arrival density, ED occupancy and hand-over were extracted from the Hospital Performance Reports by an investigator (PD). The ED has 44 cubicles/treatment areas and a median (range) occupancy of $39.6(7-69)$.

\section{Data Analysis}

Our sample size of 2,300 was based on an expected TER of $6 \%$ (found in our previous study) and a 1\% expected 95\% CI (i.e. 5\%-7\%). This was achieved by enrolling $3 \%$ of all patients who presented during the study period. A post hoc power analysis indicated that the study had a power of 0.91 to demonstrate a difference in TER between the low ED occupancy group (0-35 patients) and all other groups combined (OR 1.8, 95\%CI 1.3, 2.5).

I/AEs were analyzed and classified step-wise according to the following criteria: health care management causation, then outcome and finally preventability. ${ }^{6}$ A judgement was made regarding the strength of health care management causation and preventability using a 6-point scale (Box 2). ${ }^{6}$ Events with management causation $<50: 50$ were excluded, following the convention of HMPS. ${ }^{5}$ Events in outcome categories $1 \& 2$ fell within 
the definition of incidents; those with outcomes $3-6$ were classified as adverse events (Box 3).

Univariate and multivariate regression analysis was undertaken. Odd ratios with $95 \%$ confidence intervals $(\mathrm{CI})$ were generated for variables of interest. The level of significance was 0.05 . Statistical analysis was performed by $\operatorname{SPSS}^{\circledR}$ for Windows statistical software (version 22.0, SPSS Inc., Chicago, Illinois, USA). 


\section{RESULTS}

Of 2,169 patients enrolled, 2 were excluded (one was selected twice, the other for lack of data) leaving 2,167 for review. Two hundred and forty two were judged to have I/AEs. In 25 cases, the outcomes were considered not to be due to health care management. These were excluded, leaving 217 I/AEs for analysis.

One in 10 patients suffered an $\mathrm{I} / \mathrm{AE}$, although over half were minor incidents (Table 1). Death and serious AEs were rare (Figure 1). Approximately one third of I/AEs resulted from events prior to the index attendance, and were largely beyond ED control. Of I/AEs arising from prior care, $4.5 \%$ were ED re-attendances. The other $95.5 \%$ resulted from health care elsewhere. Most I/AEs were judged preventable (Figure 2).

The regression analysis demonstrates that ED occupancy was significantly associated with I/AEs. Using ED occupancy $<35$ as the reference group, if 36-40 or 41-45 patients were in the ED, the odds ratios for sustaining an I/AE was 2.4 and 1.8, respectively (Table 2), but was not significant with e 46 patients (OR 1.7 95\%CI 1.0-3.1). An arrival density hazard of more than 14 patients arriving in the hour of attendance 
was significant in univariate analysis (OR 1.74), but was not significant on multivariate analysis (OR 1.74, 95\%CI 0.93-3.24). Age (51-70 years) was also associated with I/AEs, (OR 1.89), but was not significant over 71 years. Higher hospital occupancy (90-99\%) had a lower odd ratio for sustaining an I/AE (OR 0.57, 95\%CI 0.35-0.92).

In multivariate analysis, there were no differences between cases and controls with regards to gender, weekend or month of presentation, triage category, time waiting to be seen by doctor or proportion treated within 4 hours, access block occupancy score, or patient hand over at the end of a shift (Table 2). Longer ED length of stay was not significant in multivariate analysis.

Errors of omission accounted for over half of I/AEs (Table 3). Errors of omission were strongly associated with the ED index attendance, errors of commission with prior events (omission: $\mathrm{ED}$ /prior 101/10, commission: $E D /$ prior $30 / 57, p<0.001)$. Diagnostic error was the most common I/AE, followed by adverse drug reactions, medication errors and postoperative complications.

The diagnostic error rate was $3.7 \%$. Of the 79 cases with diagnostic error, the diagnosis was missed in 44 . In 31 cases the diagnosis was considered 
in the differential but an alternative was preferred. In four cases the seriousness of the diagnosis was not appreciated. In subgroup analysis of patients with I/AEs, diagnostic error was strongly associated with the ED index attendance and high preventability (Table 4). Compared with other causes of I/AEs, diagnostic error was not associated with worse outcomes. Diagnostic error was attributed to cognitive error alone in $70.9 \%, 25.3 \%$ had both a cognitive and system component, while system error alone contributed only $3.8 \%$.

Adverse drug reactions (ADR) rate was $2.5 \%$. These were strongly associated with prior events (prior/ED: ADR 31/15, no ADR 36/116, $\mathrm{p}<0.001$ ). With $2 / 3$ of these prescribed, or administered elsewhere in the system, or by ambulance, 1.4\% (31 of 2167) of the ED presentations results from medications administered elsewhere in the system. Compared with other events, ADRs were significantly less likely to be judged preventable (low/ high preventability ADR 29/24, no ADR $21 / 143, \mathrm{p}<0.001)$. More serious ADRs included: complete heart block from amiodarone; ventricular tachycardia from adrenaline infusion; haematemesis, malaena, intracranial haemorrhage and epistaxis from warfarin; clostridium difficile enterocolitis from multiple antibiotics; renal failure from cisplatinum; and hypoglycemia from insulin. No 
patient in the series died from an ADR. Human error in medication delivery occurred in a further 32 cases (Table 3 ).

The relationship of outcome severity to site of events was investigated. Incidents were strongly associated with ED events, $\mathrm{AE}$ with prior events (prior/ ED incidents 26/93, AEs 41/38, p<0.001). However, the absolute numbers of AEs were similar in both groups. Thus the difference was due to a substantially higher number of ED events being minor incidents. Incidents were significantly more preventable than adverse events, with $85 \%$ judged preventable, compared with $65 \%$ of adverse events (incidents/ AEs low preventability 19/31, high preventability 110/57, $\mathrm{p}<0.001)$.

Post hoc analysis revealed the number of patients reviewed by each consultant was as follows: $501,644,482,540$. The TER detected by each consultant was $10.8 \%, 10.4 \%, 18.05 \%$ and $6.85 \%$ respectively $(\mathrm{p}<0.001)$. However, the AE rate was not significantly different $(p=0.25)$. One hundred and ten randomly selected cases were used to measure the level of agreement between the four raters. In 56 (50.9\%), all raters were in agreement about whether or not an event had occurred. In 41 (37.3\%) cases, one rater disagreed with the other three and in $13(11.8 \%)$ cases, two raters disagreed with the other two. 


\section{DISCUSSION}

Our study has demonstrated that I/AE are common in the ED setting.

Seventy-seven percent were judged preventable. The study demonstrates a complex association between ED occupancy and I/AEs, with I/AEs more likely to occur when there was high patient occupancy, but not highest occupancy. Higher hospital occupancy was protective against $\mathrm{I} / \mathrm{AEs}$. One possible explanation is that at low patient occupancy there is time to deal with a patient's problem thoroughly. As patient load increases, there is increasing need to turnover patients rapidly with a rise in error rate. At highest ED occupancy, and with higher hospital occupancy, the department becomes so congested that patient flow slows, again allowing more time to deal with patients in detail. Our data contrasts with Boden et al in the United Kingdom, who demonstrated reduced inpatient mortality, and improvement in meeting the ED 95\% 4-hour target, by lowering in-patient bed occupancy. ${ }^{13} \mathrm{~A}$ number of other studies have shown an association between ED overcrowding and inpatient mortality and other adverse events measures. ${ }^{8,9,10,14}$ 
Age 51 to 70 was also associated with I/AEs, but was not significant over 70 , although the subgroup sample size was smaller. In all age groups, the effect sizes do not differ greatly and may not be clinically significant.

We did not show an association between the access block occupancy score and ED I/AEs. Because the overcrowding hazard scale interacted with the access block occupancy score, it was excluded from the multivariate analysis.

While 'hand-over' or 'hand-offs' are a risk factor in other studies, we were not able to demonstrate this in our study. ${ }^{15,16,17}$ Attendance at weekends, in February-April (when new interns and residents start in the Australian system), waiting time, triage category, and ED length of stay were also not associated with I/AEs.

Diagnostic error was the most common cause of I/AE and was highly preventable. In the Dual Process Theory, proposed by Croskerry, type 1 thinking - fast, intuitive decision making - is though to be associated with higher diagnostic error rates, while type 2 thinking - slower, analytical decision making - with lower rates. ${ }^{18}$ This has been challenged recently. In one study, higher diagnostic accuracy was associated with more rapid responses. ${ }^{20}$ The two determinants of accuracy are case complexity and 
physician experience: complex cases had lower diagnostic accuracy; greater experience was associated with higher accuracy. ${ }^{20,21,22}$ Whatever the underlying neurophysiologic mechanism of decision-making is, reducing diagnostic error is a major challenge for emergency medicine.

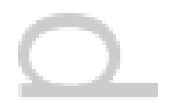

Adverse drug reactions are a common cause of AEs in our study, mostly resulting from medications prescribed by doctors or other health workers outside the ED with $45 \%$ of ADRs judged preventable. The majority of ADRs, however, arose prior to the ED index attendance. These are not amendable to correction, at least at ED level.

Incidents were judged more preventable than adverse events in this series. More serious AEs have been reported previously as more likely to be preventable or negligent. ${ }^{5,6}$ Most studies have not included incidents and our previous study had a substantially lower proportion of incidents, likely due to the screening methodology. In this study, in which EPs directly reviewed cases without a prior screening process, $59 \%$ of events were incidents.

\section{Limitations}

This study has important limitations. It was limited to a single centre, and may not be generalizable to other hospitals or health care settings. The 
inter-rater agreement in I/AEs was suboptimal. Although the definition of incidents was derived from the literature ('potential to cause patient harm'), this may have allowed excess latitude in interpretation and contributed to the difference in detection rates. Differences of opinion also became apparent, from those critical of any minor deviation from a perceived standard of care, through to those focused on serious errors and their prevention. This warrants further study. Double review was not undertaken due to human resource constraint. We did not analyse the effect of staffing mix and seniority on I/AEs because the data were clouded by overlapping processes, with multiple doctor inputs making the apportioning of responsibility in decision-making difficult in many cases. Finally, incomplete medical records and the use of only the study ED records may have led to an under-estimation of the TER rate. 


\section{CONCLUSION}

I/AEs are common in the ED and a large proportion is preventable. Our study demonstrates a complex relationship between ED occupancy and I/AEs, which requires further clarification. Strategies for prevention are urgently required.

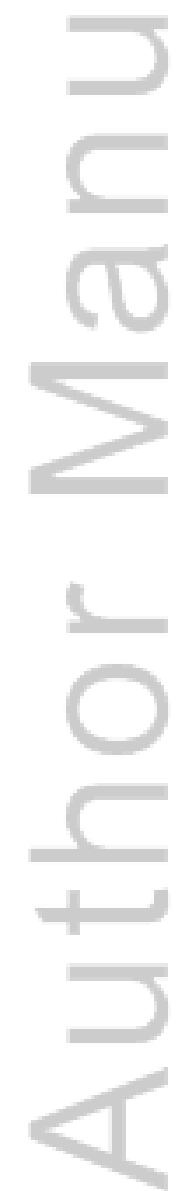

This article is protected by copyright. All rights reserved. 


\section{REFERENCES}

1. Hendrie J, Sammartino L, Silvapulle MJ, Braitberg G. Experience in adverse events detection in an emergency department: Incidence and outcome of events. Emerg.Med.Australas. 2007; 19: 16-24.

2. Hendrie J. An experience in adverse events detection in an emergency department: incidence, nature and outcome of events.

MD thesis; University of Melbourne 2004.

3. Hendrie J, Sammartino L, Silvapulle MJ, Braitberg G. Experience in adverse events detection in an emergency department: Nature of events. Emerg.Med.Australas. 2007; 19: 9-15.

4. Wolff AM, Bourke J. Detecting and reducing adverse events in an Australian rural based hospital emergency department using medical records screening and review. Emerg Med J 2002;19: 35-40.

5. Brennan TA, Leape LL, Laird NM, Hebert L, Localio AR, Lawthers AG et al. Incidence of adverse events and negligence in hospitalized patients. N Engl J Med 1991; 324: 370-6.

6. Wilson RM, Runciman WB, Gibbert RW, Harrison BT, Newby L, Hamilton JD. The quality in Australian health care study. Med J Aust 1995; 163: 458-471. 
7. Leape LL, Brennan TY, Laird N, Lawthers, A G; Localio, A R;

Barnes, B A et al. The nature of adverse events in hospitalized patients. N Engl J Med 1991:324:377-84.

8. Sprivulis PC, Da Silva J, Jacobs IG, Frazer IG, Jelinek GA. The association between hospital overcrowding and mortality among patients admitted via Western Australian emergency departments. MJA 2006; 184: $208-212$.

9. Richardson DB. Increase in patient mortality at 10 days associated with emergency department overcrowding. MJA 2006; 184: 213-216.

10. Guttmann A, Schull MJ, Vermeulen MJ, Stukel TA. Association between waiting times and short term mortality and hospital admission after departure from emergency department: population based cohort study from Ontario, Canada. BMJ 2011; 342: d2983. (Accessed Nov 2015)

11. Klasco RS, Wolfe RE, Wong M, Edlow J, Chiu D, Anderson PD et al. Am J Emerg Med 2015; 33: 1786 - 1789.

12. Harris P, Nagy S, Vardaxis N, editors, Mosby's Dictionary of Medicine, Nursing and Health Professions. $3^{\text {rd }}$ ed. 
13. Boden DG, Agarwal A, Hussain T, Martin SJ, Radford N, Riyat MS.

Lowering levels of bed occupancy is associated with decreased inhospital mortality and improved performance on the 4-hour target in a UK district general hospital. Emerg Med J 2015; 0:1-6. doi: 10.1136/emermed-2014-204479. (Accessed Nov 2015)

14. Schull MJ, Vermeulen M, Slaughter G, Morrison L, Daly P.

Emergency department crowding and thrombolysis delays in acute myocardial infarction. Ann Emerg Med 2004. 44: 586-8.

15. Richmond C, Merrick E, Green T et al. Bedside review of patient care in an emergency department: The Cow Round. Emerg.Med.Australas. 2011; 23: 600-605.

16. Ye J, Taylor DMcD, Knott JC et al. Handover in the emergency department: deficiencies and adverse effects. Emerg.Med.Australas. 2007; 19: 433-41.

17. Leroyer E, Romieu V, Mediouni Z, Becour B; Descatha A .

Extended-duration hospital shifts, medical errors and patient mortality. $\mathrm{Br}$ J Hosp Med 2014; 75: 96-101.

18. Croskerry P. Clinical cognition and diagnostic error: applications of a dual process model of reasoning. Adv in Health Sci Educ 2009; 14: $27-$ 35. 
19. Sherbino J, Dore KL, Wood TJ, Young ME, Gaissmaier W, Kreuger

S et al. The relationship between response time and diagnostic accuracy. Acad Med 2012; 87: 785-791.

20. Ilgen JS, Bowen JL, McIntyre JL, Banh KV, Barnes D, Coates WC et

al. Comparing diagnostic performance and the utility of clinical vignettebased assessment under testing conditions designed to encourage either automatic or analytic thought. Acad Med 2013; 88: 1545-1551.

21. Farrell JL, Reyna VF. Clinical gist and medical education: connecting the dots. JAMA 2009; 302:1332-1333.

22. Reyna VF. A theory of medical decision making and health: fuzzy trace theory. Med Decis Making 2008; 28: 850-865. 


\section{Box 1. Definitions}

\section{Incident}

-an untoward event that had the potential to cause patient harm although harm did not result

Adverse Event $(A E)^{6}$

-an unintended injury or complication which

-resulted in disability, death, prolongation of the hospital stay or natural history of the disease, or change in disposition and is -caused by health care management rather than the patient's disease

Disability

-temporary or permanent impairment of physical function (including disfigurement) or mental function

-subdivided into little or no disability, disability $<50 \%$ and disability

e $51 \%$ at 30 days

Prior Incident or Adverse Event

-an I/AE that arose from events before the index presentation

ED Incident or Adverse Event

-an I/AE that occurred during the index presentation

Combined Incident or Adverse Event

-an I/AE that had both prior and ED components

Arrival Density Hazard

-the number of patients arriving in the hour of index attendance

ED occupancy

-the number of patients in the ED at the end of the hour of attendance Access Block Occupancy

-the number of patients waiting more than 8 hours for an inpatient bed, at hour of attendance

Access Block Occupancy Score

$1<10 \%$ of ED beds occupied, $2=10-19 \%, 3 e 20 \%$

Hospital Occupancy Score

$1<90 \%$ acute inpatient beds occupied at midnight, $2=90-99 \%, 3=100 \%$ Overcrowding Hazard Scale

$=$ access block occupancy score $\times$ hospital occupancy score

Handover

-the thrice daily scheduled times when one shift of doctors hands over

care to the next shift of doctors

Diagnostic error

-failure of identification of a disease or condition by a scientific

evaluation of physical signs, symptoms, history, laboratory test results and procedures from the information available at the time of attendance in the ED, or might reasonable be expected to be obtainable.

Error of commission

-error undertaking treatment, task, or test

Error of omission

-failure to undertake treatment, task or test; failure to diagnose correctly 
Box 2. Levels of evidence for health care management for the two variables of causation (C) and preventability $(P)^{6}$

1. Virtually no evidence

2. Slight to modest evidence

3. $<50: 50$ but close call

4. More likely than not, $>50: 50$ but close call

5. Moderate to strong evidence

6. Virtually certain evidence

\section{Box 3. Classification of Disability Outcome ${ }^{6}$}

1. Virtually no influence on patient management

2. Minor influence on patient management

3. Prolongation of the natural history (NH) of illness/injury $\mathrm{d}$ 30 days \& no/ minimal disability

4. Prolongation of the natural history of illness/injury, with sequelae, lasting $>30$ days \&/or disability d 50\%

5. Prolongation of the natural history of illness/injury, with sequelae, lasting $>30$ days $\& /$ or resulting in permanent or major disability e $50 \%$

6. Death at 30 days 


\section{Box 4. Examples of Outcomes of Incidents and Adverse Events}

(See Boxes 2 and 3 for definitions and levels of evidence. $\mathrm{C}=$ causality, $\mathrm{P}=$ preventability)

\section{Index Presentation}

Outcome 1: Failure to administer ADT after lacerations in unimmunized patients or record status $(\mathrm{C} 6, \mathrm{P} 6)$

Outcome 2: Failure to refer Salter Harris 2 fracture to orthopaedic outpatients (C5, P5)

Outcome 3: Missed skull fracture and subdural haematoma $(\mathrm{C} 4, \mathrm{P} 4)$

Outcome 4: Tracheal perforation post intubation $(\mathrm{C} 5, \mathrm{P} 1)$

Outcome 5: Presented with constipation. New anaemia, not diagnosed or referred. Colorectal cancer metastatic at time of diagnosis 5 months later. (C5, P6)

Outcome 6: Failure to diagnose bilateral subdural haematomas. Increased confusion attributed to urosepsis. (C5, P4)

2. Resulting from events before the index presentation

Outcome 1: Hypotension from GTN and morphine administered by ambulance (C6, P5)

Outcome 2: Postoperative sternal wound infection $(\mathrm{C} 6, \mathrm{P} 1)$

Outcome 3: Clostridium difficile enterocolitis secondary to multiple antibiotics (C5, P1)

Outcome 4: Bronchopulmonary fistula and sepsis post pneumonectomy (C6, P1)

Outcome 5: None detected

Outcome 6: None detected 
Table 1. Incident and Adverse Event Rates ${ }^{\dagger}(n=2,167)$

\begin{tabular}{llll} 
& $\mathrm{n}$ & $\%$ & $(95 \% \mathrm{CI})$ \\
\hline Total Event Rate & 217 & 10.1 & $(8.8-11.4)$ \\
= Incidents (Outcome categories 1,2) & 129 & 6.0 & $(5.0-7.0)$ \\
Adverse Events (Outcome categories 3-6) & 88 & 4.1 & $(3.3-5)$ \\
$\quad$ Serious Adverse Events (Outcome 4,5) & 17 & 0.8 & $(0.5-1.3)$ \\
$\quad$ Mortality (30-day) (Outcome category 6) & 2 & 0.1 & $(0.01-0.3)$ \\
Prior Event Rate & & & \\
ED Index Event Rate & 67 & 3.1 & $(2.4-3.9)$ \\
'Combined' Event Rate & 131 & 6.0 & $(5.1-7.1)$ \\
& 19 & 0.9 & $(0.5-1.4)$ \\
Preventable Event Rate & & & \\
Diagnostic Error Rate & 167 & 7.7 & $(6.6-8.9)$ \\
Adverse Drug Reactions & 79 & 3.7 & $(2.9-4.5)$ \\
& 53 & 2.5 & $(1.8-3.2)$
\end{tabular}

${ }^{\dagger}$ Note-categories are not mutually exclusive 
Table 2. Analysis of Variables Potentially Associated with TER

Univariate Analyses

Multivariate Analyses

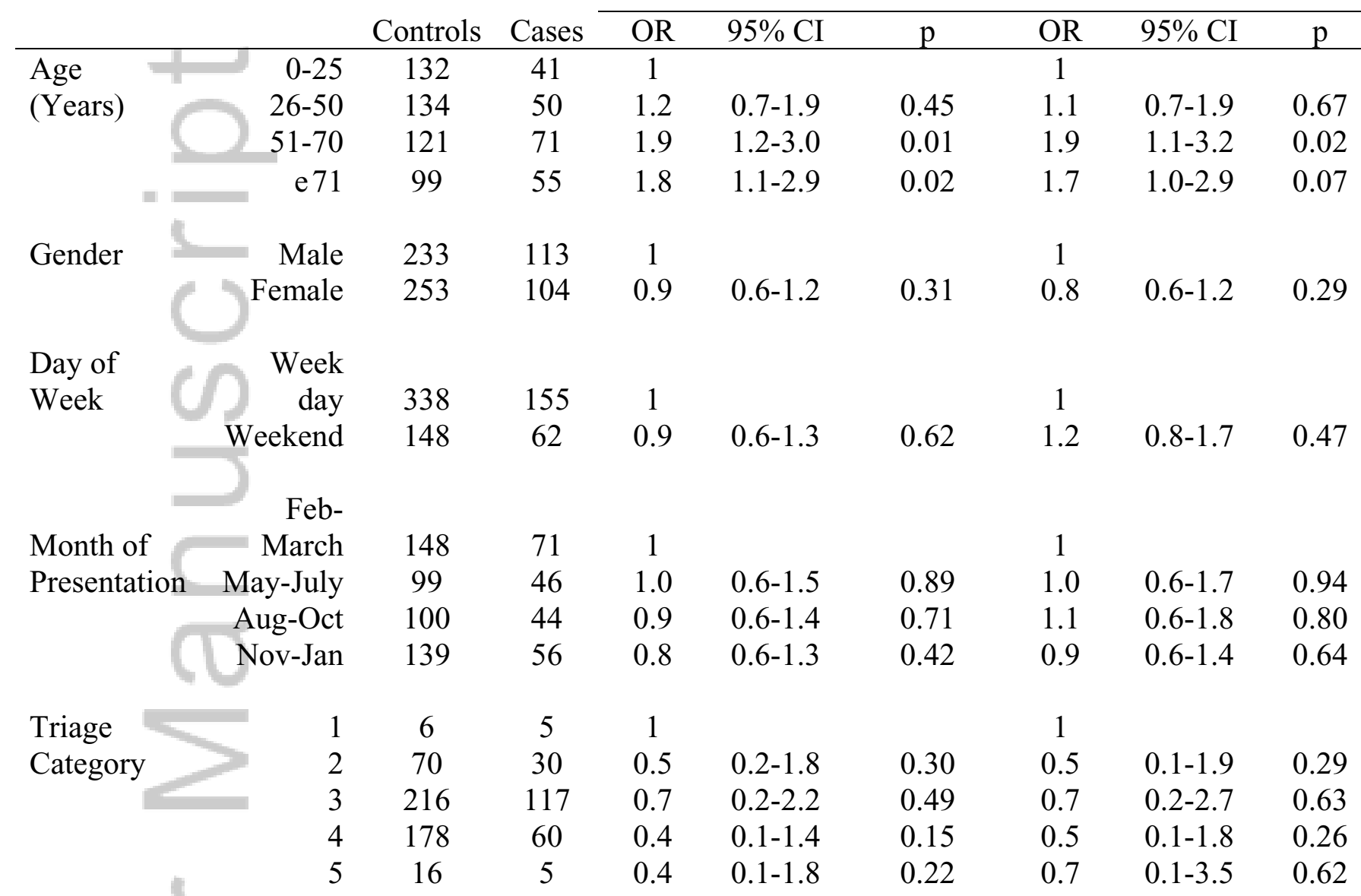

Time

$\begin{array}{lrcccccccc}\text { Waiting } & 0-10 & 174 & 72 & 1 & & & 1 & & \\ \text { To Be Seen } & 11-20 & 85 & 48 & 1.4 & 0.9-2.1 & 0.17 & 1.3 & 0.8-2.1 & 0.35 \\ \text { (Minutes) } & 21-50 & 114 & 39 & 0.8 & 0.5-1.3 & 0.41 & 0.7 & 0.4-1.2 & 0.15 \\ & \mathrm{e} 51 & 113 & 58 & 1.2 & 0.8-1.9 & 0.31 & 1.0 & 0.6-1.6 & 0.86 \\ & & & & & & & & & \\ \text { Arrival } & 0-7 & 146 & 50 & 1 & & & 1 & & \\ \text { Density } & 8-10 & 116 & 55 & 1.4 & 0.9-2.2 & 0.16 & 1.2 & 0.7-2.0 & 0.46 \\ \text { Hazard } \dagger & 11-13 & 130 & 56 & 1.3 & 0.8-2.0 & 0.32 & 1.2 & 0.7-2.0 & 0.63 \\ & \mathrm{e} 14 & 94 & 56 & 1.7 & 1.1-2.8 & 0.02 & 1.7 & 0.9-3.2 & 0.08\end{array}$

$\begin{array}{lrcccccccc}\text { ED } & 0-35 & 186 & 56 & 1 & & & 1 & & \\ \text { Occupancy } \dagger & 36-40 & 78 & 51 & 2.2 & 1.4-3.5 & <0.01 & 2.4 & 1.4-4.0 & <0.01 \\ & 41-45 & 89 & 46 & 1.7 & 1.1-2.7 & 0.02 & 1.8 & 1.0-3.2 & 0.04 \\ & \mathrm{e} 46 & 133 & 64 & 1.6 & 1.1-2.4 & 0.03 & 1.7 & 1.0-3.1 & 0.07\end{array}$

$\begin{array}{lrcccccccc}\text { No. Pts } & 0-10 & 167 & 63 & 1 & & & 1 & & \\ \text { Discharged } & 11-12 & 59 & 29 & 1.3 & 0.8-2.2 & 0.33 & 1.1 & 0.6-1.9 & 0.85\end{array}$ 


$\begin{array}{lrllllllll}<4 \text { Hours } & 13-16 & 147 & 70 & 1.3 & 0.8-1.9 & 0.26 & 0.9 & 0.5-1.6 & 0.75 \\ & \mathrm{e} 16 & 113 & 55 & 1.3 & 0.8-2.0 & 0.25 & 0.9 & 0.5-1.6 & 0.66\end{array}$

Access

$\begin{array}{lrrrrrrrrr}\text { Block } & <10 \% & 127 & 50 & 1 & & & 1 & & \\ \text { Occupancy } & 10-19 \% & 173 & 88 & 1.3 & 0.9-2.0 & 0.23 & 1.2 & 0.8-1.9 & 0.37 \\ \text { Score } \dagger & \mathrm{e} 20 \% & 186 & 79 & 1.1 & 0.7-1.6 & 0.72 & 1.1 & 0.6-1.8 & 0.81\end{array}$

$\begin{array}{lllll}\text { ED Total } & 0-190 & 125 & 66 & 1\end{array}$

Daily $\quad 191-200 \quad 96 \quad 42 \quad 0.8$

Attendance

201-210

$138 \quad 45 \quad 0.6$

(n)

e 210

127

$64 \quad 1.0 \quad 0.6-1.5$

0.43

$0.5-1.3$

0.04

0.7

$0.4-1.2$

0.24

Hospital $\quad \begin{array}{rcc}<90 \% & 74 & 46\end{array}$

1

0.7

$0.4-1.0 \quad 0.05$

0.7

0.4-1.1

0.13

Occupancy

$412 \quad 171$

$0.8 \quad 0.5-1.4$

0.51

$\begin{array}{lrrrrrrrrr}\text { ED Length } & 0-150 & 139 & 42 & 1 & & & 1 & & \\ \text { of Stay } & 151-250 & 139 & 72 & 1.7 & 1.1-2.7 & 0.02 & 1.6 & 1.0-2.7 & 0.07 \\ \text { (Minutes) } & 251-350 & 86 & 43 & 1.7 & 1.0-2.7 & 0.05 & 1.3 & 0.7-2.5 & 0.38 \\ & \mathrm{e} 351 & 122 & 60 & 1.6 & 1.0-2.6 & 0.04 & 1.5 & 0.8-2.8 & 0.24\end{array}$

Patient

none

$209 \quad 89 \quad 1$

Handed

once 254

115

1.1

1.1
1.3

$0.8-1.5$

$0.6-2.7$

0.72

0.44

1

e 23

13

0.8

0.9

$0.5-1.2$

0.33

0.4-2.3 0.88

${ }^{\dagger}$ see Box 1 for definitions

This article is protected by copyright. All rights reserved. 
Table 3. Nature of Incidents and Adverse Events versus Type of Error $\begin{array}{lccc}\text { Nature of Incidents and Adverse } & \begin{array}{c}\text { Error of } \\ \text { Omission }\end{array} & \begin{array}{c}\text { Error of } \\ \text { Commission }\end{array} & \text { Totals } \\ \text { Events } & \end{array}$

(n) (n)

Diagnostic Errors

Adverse Drug Reactions 73

3

82

Post operative complications

0

43

46

Laboratory, other investigative

15

23

23

issue/ Test not ordered

$\mathrm{No} /$ wrong medication given

8

0

15

Other medication errors

Post ED procedural

8

6

14

84

12

complications

Excess medication dose errors

1

7

8

Inadequate physical examination/

0

5

$\begin{array}{ll}6 & 6\end{array}$

observations

Other

5

0

5

Totals

118

$1 \quad 6$

99

217


Table 4. Diagnostic Error and associations

$\begin{array}{lll}\text { Diagnostic } & \text { No Diagnostic } & p \\ \text { Error }(n=79) & \text { Error }(n=138) & \\ \% & \% & \end{array}$

Location of Events

\begin{tabular}{llll} 
Prior to ED & 6.3 & 44.9 & $<0.001$ \\
\hline ED events & 83.5 & 47.1 &
\end{tabular}

Preventability

$\begin{array}{llll}\mathrm{High}^{\dagger} & 97.5 & 65.2 & <0.001 \\ \text { Low }^{\ddagger} & 2.5 & 34.8 & \end{array}$

Outcome severity Adverse event 48.1 36.2 0.09 Incident 51.9 63.8

${ }^{\dagger}$ levels of evidence 4-6 Box 2 ${ }^{\ddagger}$ levels of evidence 1-3 Box 2 


\section{OUTCOME}

$\mathrm{N}=217$

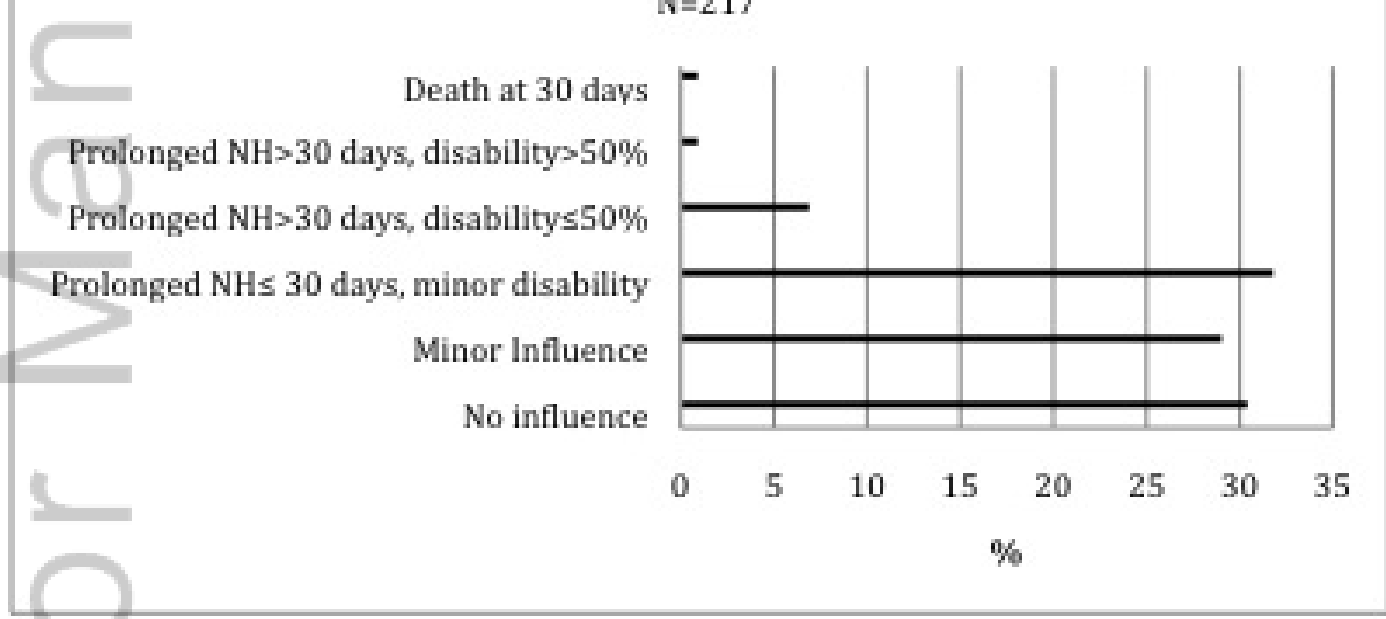

Figure 1 Outcome Tiff.tiff

This article is protected by copyright. All rights reserved. 


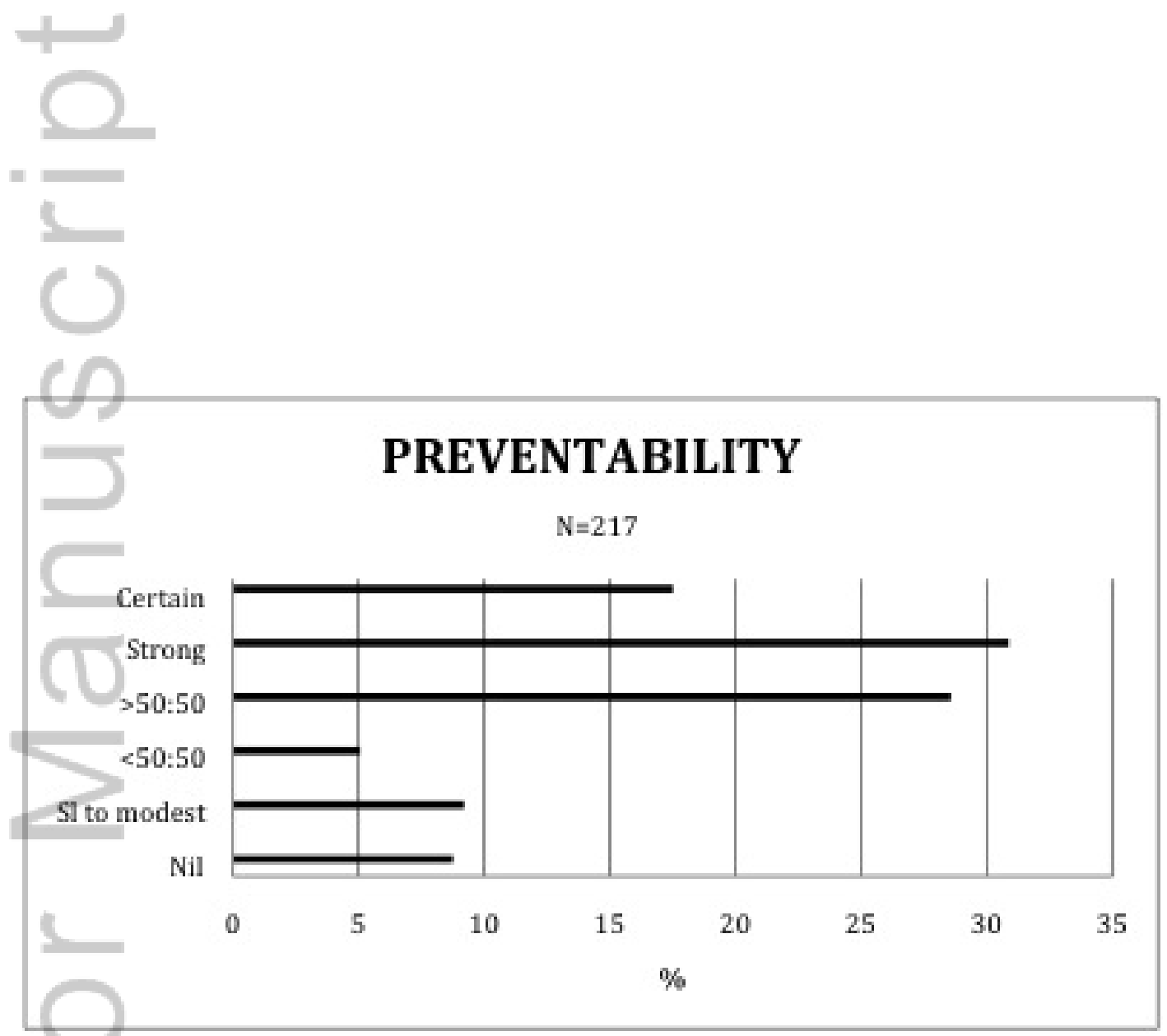

Figure 2 Preventability Tiff.tiff

This article is protected by copyright. All rights reserved. 


\section{University Library}

\section{- M M N E R VA A gateway to Melbourne's research publications}

Minerva Access is the Institutional Repository of The University of Melbourne

Author/s:

Hendrie, J;Yeoh, M;Richardson, J;Blunt, A;Davey, P;Taylor, D;Ugoni, A

Title:

Case-control study to investigate variables associated with incidents and adverse events in the emergency department

Date:

2017-04-01

Citation:

Hendrie, J., Yeoh, M., Richardson, J., Blunt, A., Davey, P., Taylor, D. \& Ugoni, A. (2017).

Case-control study to investigate variables associated with incidents and adverse events in the emergency department. EMERGENCY MEDICINE AUSTRALASIA, 29 (2), pp.149-157. https://doi.org/10.1111/1742-6723.12736.

Persistent Link:

http://hdl.handle.net/11343/292352 